\title{
2 \\ Improvements in Urban Sub-Catchment Runoff Modeling
}

\begin{abstract}
Allan G. Goyen
This chapter describes the development of an improved sub-catchment runoff modeling technique for urban catchments to help overcome problems of parameter scaling and process lumping inherent in many existing schemes. The development is based on five years of detailed monitoring of a typical urban catchment in Canberra, Australia utilising nested rainfall and flow gauges to characterise the accumulation of runoff throughout the catchment during a wide range of storm events. The gauging network provided data to interpret lot scaled process units and their accumulation throughout the 90 hectare (ha) catchment. The detailed rainfall/runoff data led to a modified modeling approach that incorporated lot scaled process definition and the means to cumulate these to any size catchment. Independent testing of the procedure was carried out on a separate catchment in Sydney. The approach also provided the means to further test different lot scale drainage provisions and their effect at different catchment scales.
\end{abstract}

\subsection{Introduction}

The hydrologic response of many drainage systems to apparently similar storm events can vary significantly due to different routing characteristics. Failure to take into account these internal, or intra-catchment, processes has often limited the usefulness of simplified estimating procedures. The literature includes many instances where numerical runoff simulation procedures provide relatively poor

Goyen, A.G. 2002. "Improvements in Urban Sub-Catchment Runoff Modeling." Journal of Water Management Modeling R208-02. doi: 10.14796/JWMM.R208-02.

(C) CHI 2002 www.chijournal.org ISSN: 2292-6062 (Formerly in Best modeling practices for Urban Water Systems. ISBN: 0-9683681-6-6) 
estimating accuracy under a range of circumstances (Aitken, 1975; Bufill, 1989). Because intra-catchment data have been unavailable, relatively simplistic, single parameter models, including the storage routing, time/area and kinematic wave approaches, have been used to represent the often-complex array of processes occurring across an urban catchment. The research by Goyen (2000) described in this chapter sought to add to the urban catchment modeling knowledge base, and to improve runoff estimation techniques. This required the measurement of rainfall and runoff at nested gauging sites, within typical urban catchments, to build a greater understanding of the way that runoff accumulates throughout the catchments and how it responds to different storm inputs. New approaches to estimating runoff were then investigated.

A major problem with urban runoff simulation is the definition of the drainage of individual housing, both individually and cumulatively, through the associated communal drainage system. This is true when individual lot inputs are combined with hydraulic modeling of the drainage system, or when larger sub-catchments are used to estimate the accumulated input of large numbers of lots together with the associated road drainage.

Even at the lot level, sub-catchment runoff is complex, involving contributions from roofs, yards and adjacent roads and footpaths. The effective rainfall excess from different areas is also subject to different infiltration regimes. Pervious areas are the most variable. Although many urban areas appear similar to the casual observer, their runoff response can vary significantly, often as a result of differing local government drainage policies and practices. Different government policies in respect to required lot fencing, roof drainage and inter-lot drainage can contribute to changes in runoff response at an lot as well as total catchment scale.

\subsection{Background}

To illustrate the type of problems that can be exhibited in many current subcatchment runoff simulation methodologies, Table 2.1 summarizes the results by Aitken (1975) for the 70 ha Vine Street urban catchment in Melbourne, Australia. The results are based on the runoff routing procedure by Laurenson (1964) to estimate runoff hydrographs from known rainfall data.

The storage routing procedure is based on the equation $S=B_{a v} Q^{n-1}$ where $S$ is the surface storage on the catchment, $B_{a v}$ is a fitting parameter relating to the catchment average storage delay time, $Q$ is the instantaneous discharge rate and $n$ is a further fitting parameter relating to the runoff response non-linearity. The results in Table 2.1 are based on a fixed value of $n=-0.285$. 
Table 2.1 Vine Street urban catchment, Melbourne (Aitken, 1975).

\begin{tabular}{lccl}
\multicolumn{1}{c}{ Date } & $\begin{array}{c}\text { B } \\
\text { determined } \\
\text { from calibration }\end{array}$ & $\begin{array}{c}\text { Observed } \\
\text { Peak } \\
\left(\mathrm{m}^{3} / \mathrm{s}\right)\end{array}$ & $\begin{array}{c}\text { Computed Peak } \\
\left(\mathrm{m}^{3} / \mathrm{s}\right)\end{array}$ \\
\hline 5 Nov. 1971 & 0.17 & 0.31 & $0.42(35.5 \%)$ \\
6 Nov. 1971 Peak 1 & 0.22 & 0.93 & $1.70(82.8 \%)$ \\
6 Nov. 1971 Peak 3 & 0.16 & 1.12 & $1.20(7.1 \%)$ \\
24 Dec. 1971 Peak 1 & 0.05 & 0.40 & $0.11(-72.5 \%)$ \\
24 Dec. 1971 Peak 2 & 0.06 & 0.58 & $0.26(-55.2 \%)$ \\
11 Feb. 1972 Peak 1 & 0.12 & 0.92 & $0.80(-13.0 \%)$ \\
11 Feb. 1972 Peak 2 & 0.17 & 1.07 & $1.22(14.0 \%)$ \\
12 Feb. 1972 & 0.065 & 0.39 & $0.15(-61.5 \%)$ \\
& $\mathrm{B}_{\text {av. }}=0.13$ & & \\
\hline
\end{tabular}

The work, although not setting out to do so, indicated that the adopted " $B$ " parameter for individual events, to maintain the best fit between gauged and simulated runoff hydrograph peaks, often differed from the $B_{a v}$ value by a significant magnitude. The resulting simulated discharge peaks based on $B_{a v}$, in some instances, also varied significantly from the gauged results.

The work by Goyen (2000) postulated that the indicated variance was not, as originally suspected, due to data errors, but was more likely due to limitations in the modeling approach when simulating rainfall/runoff response during different storm events, even with the same apparent magnitude.

The root of the problems highlighted was expected to be found from more detailed urban catchment rainfall runoff data. The current research program therefore included the comprehensive monitoring of continuous rainfall and runoff from specially designed and constructed stations at strategic locations within typical urban catchments in Canberra, Australia. This was aimed at isolating as many individual runoff processes as possible. The subsequent research involved the rigorous analysis of the collected data at varying intracatchment scales and the formulation and testing of an appropriate scaleindependent approach to sub-catchment modeling, capable of operating in either an event or continuous mode, and under vastly different rainfall and antecedent conditions.

\subsection{Research Catchment and Gauging Network}

The 90.7 ha Giralang catchment in Canberra, selected as the main study site, has been gauged by the Canberra Government since 1976. Goyen (1981) and Bufill (1989) have previously used this well-documented, gauged urban catchment to develop and test simplified numerical procedures. A description of the gauging program proposed at the beginning of this research is provided 
by Goyen and O'Loughlin, (1993). The locations of the primary installed gauges are shown in Figure 2.1. The Giralang catchment includes 19.6 ha of pasture in its upper part, with 62.9 ha of fully developed residential area downstream. It has a piped stormwater drainage system, with an oversized trunk pipe system that allowed access for setting up flow gauges in addition to the weir at the catchment outlet.

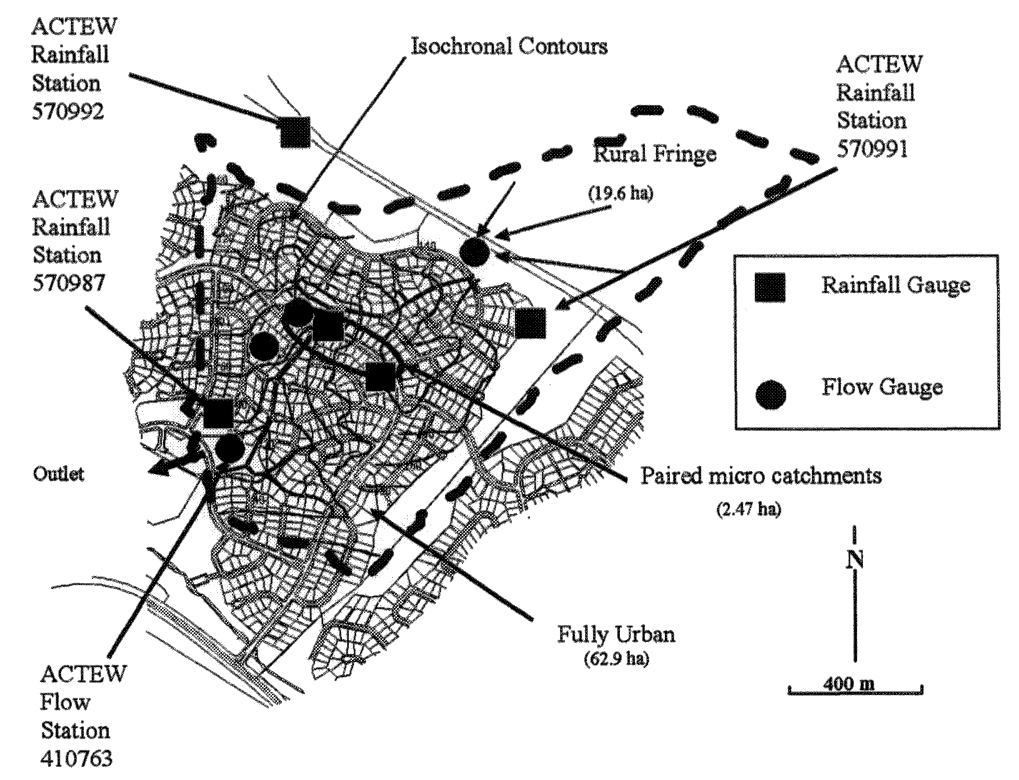

Figure 2.1 Giralang catchment and gauging stations.

\subsubsection{Giralang Paired Micro Catchments}

As indicated in Figure 2.1, a pair of micro-catchments, nested within the total catchment, were set up near the centre of the urban part of the catchment. These are shown in detail in Figure 2.2 and were selected to allow separation of the typical drainage processes occurring with roof, yard and road runoff. Flow gauges were established at the outlets to these catchments, in 300 and 450 mm diameter pipes, and in a $900 \mathrm{~mm}$ pipe at the boundary between the rural and urban areas, to measure rural flows. Two rainfall pluviographs were established within the paired micro catchments to isolate spatial variations, and to enhance the spatial coverage of the long-term network of three rainfall gauges close to the catchment. Detailed continuous data could be recorded at a time step resolution of 30 seconds or less. 


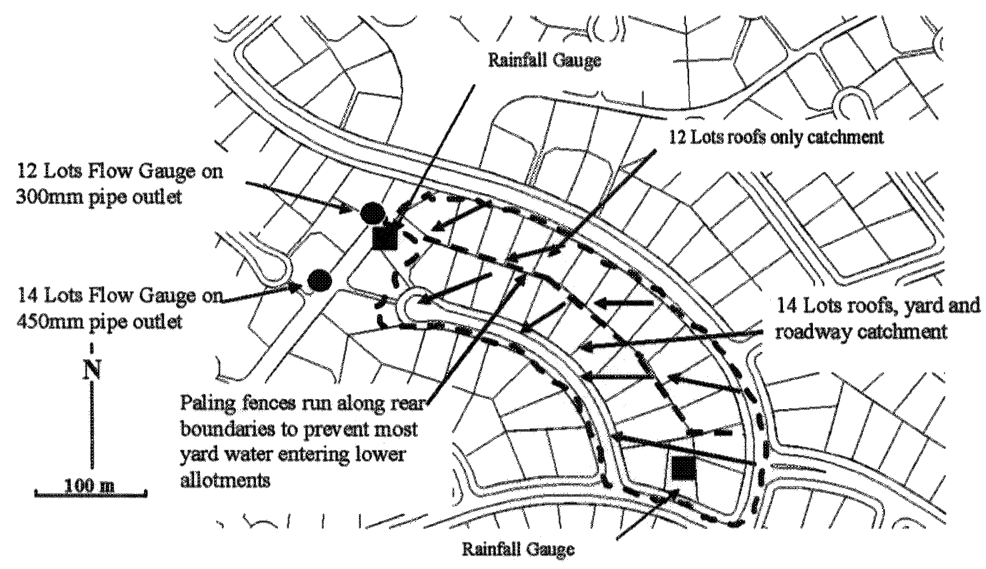

Figure 2.2 Giralang paired micro-catchments.

\subsubsection{Spence Roof Gauge}

After consideration of preliminary results from the Giralang paired microcatchments, another micro-catchment indicated in Figure 2.3 was established in 1995 at Spence, adjacent to the Giralang catchment. This was designed to measure runoff from a $47 \mathrm{~m}^{2}$ roof plane. The measured roof runoff was thereby isolated from the effects of the connected piped drainage across the yard to the lot boundary. A V-notch weir runoff gauge was positioned at the bottom of the down pipe draining the roof plane. A rainfall station, using a $0.2 \mathrm{~mm}$ tipping

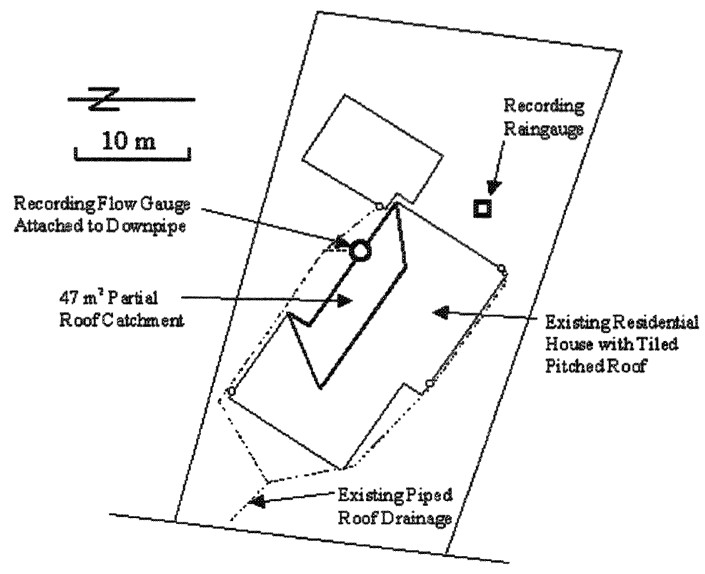

Figure 2.3 Spence single residential roof-catchments. 
bucket pluivograph, was established within the property to measure local rainfalls as well as monitor spatial differences between it and the Giralang sites. The recorder time step was set at 20 seconds to ensure appropriate data response from this small catchment area.

\subsection{Analysis of Monitored Data}

Continuous rainfall and runoff data was collected between 1993 and 1996 within the Giralang catchment. An extraordinary set of storms were monitored over this period, with over 60 flood peaks in excess of $1 \mathrm{~m}^{3} / \mathrm{s}$ being observed. This included 24 events that exceeded 1 year return period, 6 that exceeded 2 year return period, 4 that exceeded 5 year return period and 1 that exceeded 8 year return period. Residential roof rainfall and runoff were also collected over most of 1995 at the nearby Spence site. The resolution and breadth of the collected gaugings provided sufficient spatial and temporal information to examine the intra-catchment processes that collectively determine runoff characteristics for any given event. The initial analysis of the collected data was directed at examining individual process types and comparing one to another.

The initial analysis, using the collected data, included the calibration and examination of results from a number of currently used runoff routing procedures. This analysis was used to further quantify present limitations and possible directions where the procedures could be enhanced. The results using the EPA SWMM runoff routing procedure are summarised in Tables 2.2 and 2.3.

Calibration of the 2.47 ha combined 26 alottment catchment indicated in Figure 2.2, based on six events, resulted in an average catchment width (W) parameter of $638 \mathrm{~m}$. Table 2.2 summarizes the results for the six events.

Table 2.2 Calibration results for the 26 allotments 2.47 hectare Giralang paired micro catchments using EPA SWMM.

\begin{tabular}{cccc}
\hline Event & $\begin{array}{c}\text { Return Period } \\
(\text { Yrs. }\end{array}$ & $\begin{array}{c}\text { Calibrated W } \\
(\mathrm{m})\end{array}$ & $\begin{array}{c}\text { Simulated } \mathrm{Q}_{\mathrm{p}} \% \text { error relative } \\
\text { to Qoberved using Wav }\end{array}$ \\
\hline 1 & $<1$ & 1100 & -3.3 \\
2 & 6 & 1200 & -8.1 \\
3 & $<1$ & 380 & 12.8 \\
4 & 8 & 500 & 4.5 \\
5 & 2.5 & 400 & 9.8 \\
6 & 1.1 & 250 & 43.0 \\
\hline
\end{tabular}


Validation results based on a further six independent events using the calibrated average $\mathrm{W}_{\mathrm{av}}$ of $638 \mathrm{~m}$ are summarized in Table 2.3.

Tables 2.2 and 2.3 indicate the same magnitude of differences about the mean as reported in the results by Aitken (1975) using a different lumped runoff routing approach on a different urban catchment 28 times larger.

Table 2.3 Validation results for the 26 allotments 2.47 hectare Giralang paired micro catchments using EPA SWMM.

\begin{tabular}{cccc}
\hline Event & $\begin{array}{c}\text { Return Period } \\
(\text { Yrs. }\end{array}$ & $\begin{array}{c}\text { Best W } \\
(\mathrm{m})\end{array}$ & $\begin{array}{c}\text { Simulated Qp \% error } \\
\text { using Calibrated Wav }\end{array}$ \\
\hline 7 & $<1$ & 250 & 22.0 \\
8 & 1.1 & 450 & 7.6 \\
9 & $<1$ & 450 & 25.5 \\
1 & 1 & 800 & -2.5 \\
11 & $<1$ & 380 & 19.6 \\
12 & 1.1 & 300 & 42.5 \\
\hline
\end{tabular}

Calibration, using the EPA SWMM runoff procedure, of the total 62.9 ha Giralang urban catchment, using the same storm events summarised in Table 2.2 , resulted in an average $(W)$ parameter of $8250 \mathrm{~m}$. This resulted in a W/L (L equals the effective catchment length by dividing the catchment area by the calibrated average $\mathrm{W}$ ) ratio of 108 . The corresponding $\mathrm{W} / \mathrm{L}$ ratio for the similar constituent 2.47 ha Giralang paired micro catchment, illustrated in Figure 2.2, was 16.5 .

The significant differences in respective $\mathrm{W} / \mathrm{L}$ ratios also illustrate some of the probable limitations in the transference of even calibrated modeling parameters between different sub-catchments within the same watershed.

After this analysis, the progressive building of a "process tree" approach to runoff simulation began, to better describe the accumulation of the various process components in forming total catchment runoff.

Further research utilising the collected data concentrated on the division between the attenuating or "routing" processes at an lot scale and those within the communal, piped drainage system. Within the communal system a further division between superposition effects and in-pipe storage attenuation was examined. Several existing software packages were adopted to interrogate the collected data. This included a development version of the XP-RAFTS numerical Rainfall/Runoff network routing computer program (Goyen et al., 1993) that was used as a "decision support work bench" to assess and test different processes. The XP-EXTRAN hydraulic analysis software (Goyen et al., 1993) was also used to assess in detail the superposition and in-pipe attenuation effects. 
These tools were used to build a "process tree" approach that accounted for the accumulation of processes occurring at scales from a single residential lot area up to a total urban catchment incorporating distributed lots, road systems and a networked drainage system.

The results from both the Spence roof catchment and the Giralang 12 roof catchment were subsequently applied to the adjacent Giralang 14 lot catchment that also included yard and adjacent road drainage elements. The XP-RAFTS network was further developed to represent these, as shown in the network representation in Figure 2.4. The most appropriate routing models for both the roof and road nodes were found to be a single linear storage. Yard runoff more aptly fitted to a single non-linear storage routing model. Additionally, level pool routing was applied to simulate roof gutter storage, detention behind fencing and storage within the in-yard piped roof drainage system. Simple lagging between individual processes and between individual lots was applied. Alternate small and large storm events were examined to isolate road and yard runoff. It was observed that during prolonged, intense storms, a small amount of sub-soil drain water was also added to the later part of the runoff process. This input was isolated by measuring the recession flows at the outlet of the Giralang 12 roof catchment after the cessation of roof gutter flow and after a reasonable time to allow for normal pipe flow to outlet. It was noted that flows from this very small catchment, on some occasions, persisted for up to 1 hour following sustained rainfall.

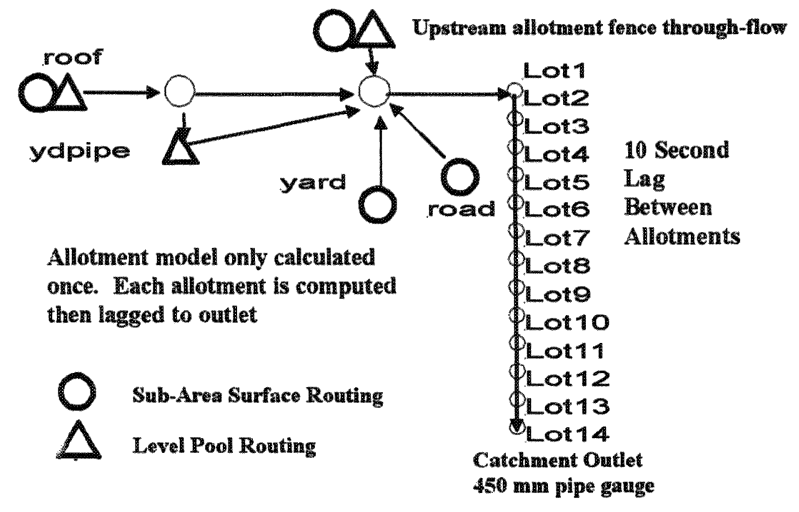

Figure 2.4 Giralang 14 roof, yard and road model.

Figure 2.5 shows a typical validation result from the 14 lot Giralang catchment for 1.5 year return period storm event. Average areas for roof, yard and road elements were applied to each of the 14 lots. One of the additional findings from this analysis was that pervious area infiltration could be 


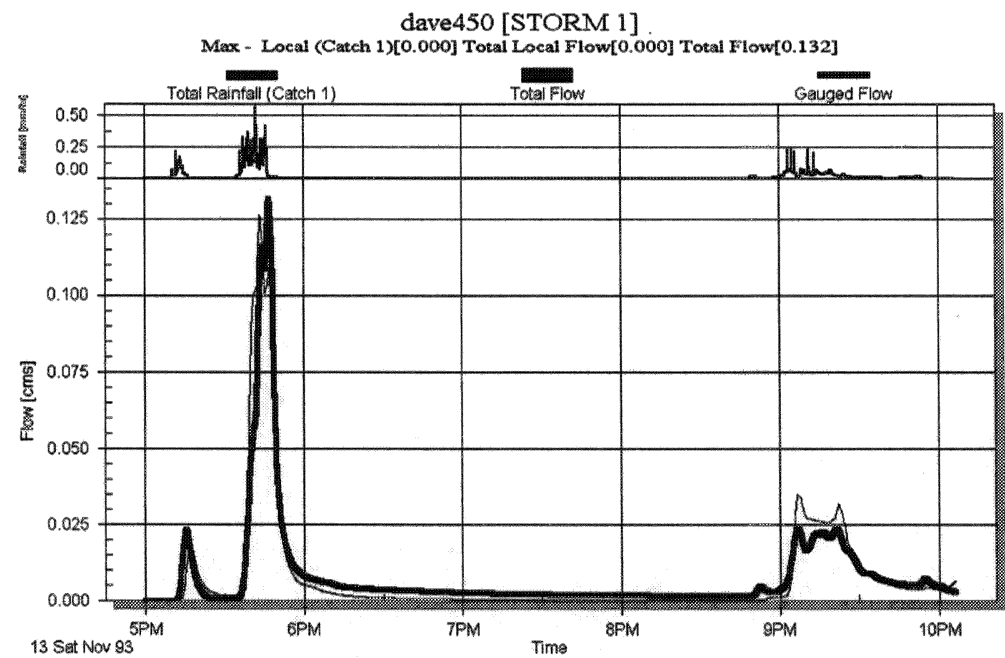

Figure 2.5 14 Allotments 1.5 hectare micro-catchment modeled and gauged hydrographs for the 13/11/93 event. (flows are in $\mathrm{m}^{3} / \mathrm{s}$, time in hours).

characterised by a proportional loss rate of between $50 \%$ and $100 \%$ of the rainfall. An alternative, more physically-based approach, utilising a spatially variable water balance model, provided comparable results to the proportional loss. The water balance model was also found to be more appropriate for use in a continuous simulation context (Goyen and O'Loughlin, 1999).

The fit between observed and simulated hydrographs over the period of simulation is satisfactory. The continuous water balance modeling approach, to estimate rainfall excess, is shown to reasonably replicate inter-storm as well as storm periods.

\subsection{Runoff Attenuation due to Distribution of Allotment Runoff and Pipe Network Routing}

The analysis then considered the extension of the micro catchment models, described above, to the total Giralang catchment. The "process tree" model described in Figure 2.4 included lagging links representing either the rear boundary drainage line or the pipe drain under the road to the gauged outlet. When the lots were considered as parallel elements with zero lags, the estimated peaks over a wide range of storm events differed significantly, by between $3.7 \%$ and $23.4 \%$, from the peaks from the corresponding 10 second lag models. 
Times of hydrograph rise were also found to be earlier than observed values. It was hypothesised that the shape of the particular rainfall hyetograph about the peak had a significant effect on the resulting runoff peak, due to different superposition effects. It was argued that rainfall events with sharp recessions about the their peak intensity, when lagged to the outlet from different subcatchment locations, could possibly accumulate a lower peak discharge than other rainfall events with similar peak intensity and flatter recessions.

To further verify this, the combined gauged runoff peak from the Giralang paired micro-catchments, indicated in Figure 2.2, was compared to the total Giralang gauged runoff peak during a large number of storm events. It was observed that the ratio of runoff peak at the 62.9 ha outlet divided by the runoff peak at the outlet of the paired micro-catchments ranged between 21 and 37. This further supported the hypothesis that variable superposition had to be incorporated into any model structure that intended to represent changing storm temporal characteristics and varying catchment scale. XP-EXTRAN was used to route Giralang micro catchment recorded flow inputs at various nodes defining the total trunk drainage system for the 62.9 ha Giralang catchment. The results from this analysis confirmed the minimal effects of in-pipe storage and the dominant role of superposition.

\subsection{Proposed Total Catchment Modeling Approach}

The above analysis pointed to a new approach to urban sub-catchment modeling. It indicated that it was possible to create a "process tree" model for a typical individual lot drainage system and then to progressively extend this to larger and larger catchment scales incorporating the communal or public piped drainage system. An individual lot's runoff can be represented by relatively simple storage routing models that can account for all significant runoff processes including roofs, associated roads, paths and yard areas as well as fencing policies or any additional storage devices. Figure 2.6 for example includes processes to account for fence through-flow emanating from immediate upstream lots. A sub-catchment or total catchment can be discretised into sub-areas based on the communal drainage (external to lots) flow times and isochronal contours. Each sub area can be equated to the number of enclosed lots. The lot output hydrograph is then multiplied by the total number of lots in each isochronal area. Each isochronal total hydrograph is then appropriately lagged to the catchment outlet based on the isochronal time step. The proposed approach is scale-independent as it is based on a representative lot output. It will also reflect superposition effects subject to varying storm shape via the isochronal lagging. 


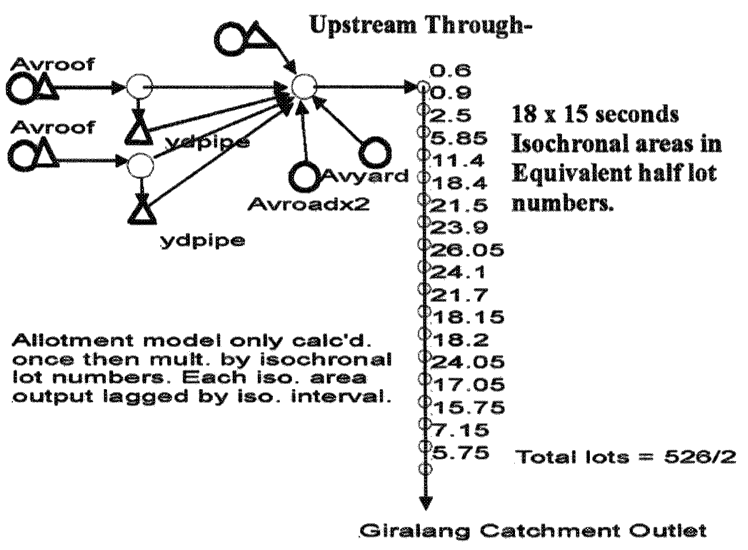

Figure 2.6 Giralang 526 allotments total urban catchment "Process Tree" model.

The proposed "process tree" model for the total 62.9 ha Giralang urban catchment is further described in Figure 2.6. The model is essentially the same as that described in Figure 2.4 for a 1.5 ha catchment. The only difference relates to the inclusion of the fencing characteristics that preclude some $50 \%$ of yard flows fully adding to the storm peaks.

Figure 2.7 shows the simulated runoff result for the 1.5 year return period. event of the 13/11/93 for the total $62.9 \mathrm{ha}$ Giralang catchment. This event is the same as that included in Figure 2.5 acting on the 1.5 ha 14 lot catchment.

The results indicated in Figures 2.5 and 2.7 from the 1.5 and 62.9 ha catchments simulations are very similar. The representative lot routing parameters for the roof, yard and roadway processes described in Figure 2.4, calibrated from a single multi peak storm in 1993, were used in all further validation models of the 12,14 and 526 lot Giralang sub-catchments.

This comparative result between the 1.5 ha and 62.9 ha catchment models was common to the 29 validation events used. The overall accuracy of the procedure was further tested utilising multi-peak events with significant ranges in peak magnitude as well as antecedent conditions. The procedure performed satisfactorily over a wide range of situations on the 12,14 and 526 lot Giralang sub-catchments.

A summary of the peak errors from the 29 validation events are provided in Tables 2.4 and 2.5 for the 1.5 ha and 62.9 ha Giralang catchments respectively.

The first column of results in Tables 2.4 and 2.5 indicate that the results were similar for the 1.5 ha and 62.9 ha catchment models with only $31-34 \%$ of the events modeled having errors in peak, relative to the observed values, 


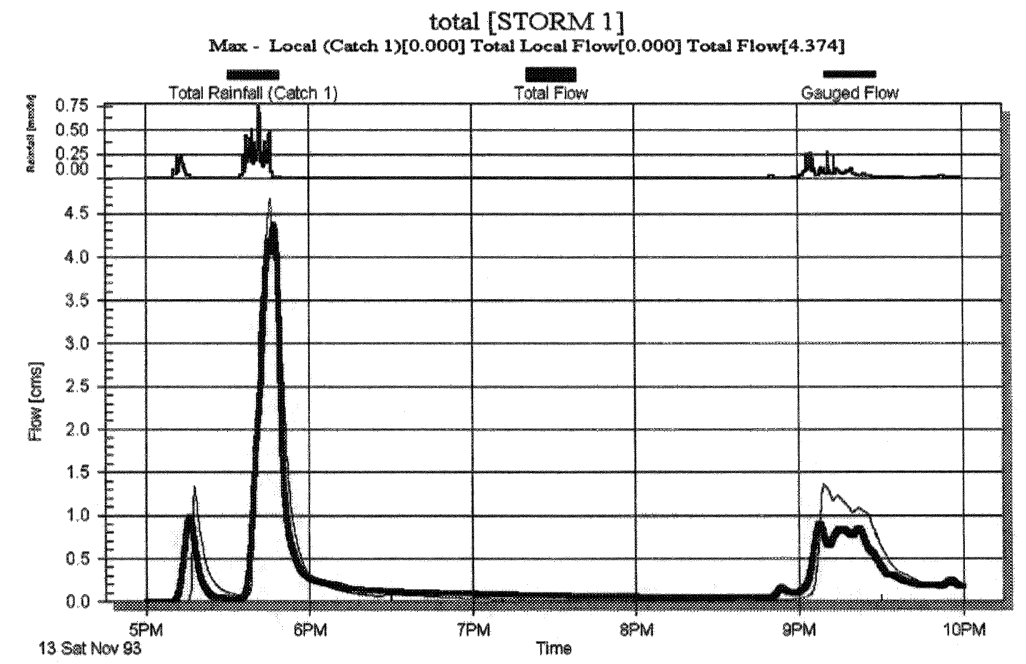

Figure 2.7 Giralang 526 allotments 62.9 hectare urban catchment modeled and gauged hydrographs for the 13/11/93 event (flows are in $\mathrm{m}^{3} / \mathrm{s}$, time in hours).

above $10 \%$ and $3 \%$ of the events having peak error above $20 \%$. This is in contrast to the results, using the same data, modeled with the XP-RAFTS nonlinear runoff routing program (Goyen et al., 1993). These results, for the

Table 2.4 Giralang catchment error analysis based on "Process Tree" model results for 14 allotment, 1.5 ha micro-catchment.

\begin{tabular}{cc}
$\begin{array}{c}\text { \% of } 29 \text { Modeled Independent } \\
\text { Events }\end{array}$ & $\begin{array}{c}\text { Absolute Error } \\
\text { Abs[Qpeak(est)/Qpeak(obs)x 100.0] }\end{array}$ \\
\hline $0 \%$ & $>50 \%$ \\
$0 \%$ & $>40 \%$ \\
$0 \%$ & $>30 \%$ \\
$3 \%$ & $>20 \%$ \\
$31 \%$ & $>10 \%$ \\
\hline
\end{tabular}

Table 2.5 Giralang catchment error analysis based on "Process Tree" model results for total 62.9 ha urban catchment.

\begin{tabular}{cc}
$\begin{array}{c}\text { \% of } 29 \text { Modeled Independent } \\
\text { Events }\end{array}$ & $\begin{array}{c}\text { Absolute Error } \\
\text { Abs[Qpeak(est)/Qpeak(obs)x100.0] }\end{array}$ \\
\hline $0 \%$ & $>50 \%$ \\
$0 \%$ & $>40 \%$ \\
$0 \%$ & $>30 \%$ \\
$3 \%$ & $>20 \%$ \\
$34 \%$ & $>10 \%$ \\
\hline
\end{tabular}


62.9 ha catchment, indicated $69 \%$ of the events $>10 \%$ error, $31 \%$ of the events $>20 \%$ error and $10 \%$ of the events $>30 \%$ error. The time-area method produced similar results to XP-RAFTS.

Additionally, the overall mean of the difference between estimated and gauged peaks for all validation peaks was $-0.6 \%$ and $-3.6 \%$ for the 1.5 ha and 62.9 ha catchments, respectively. The bias in the mean values was considerably less than equivalent event values utilising either single storage routing models or the time-area method (Bufill, 1989; Goyen, 2000) that were $-23 \%$ and $17 \%$, respectively, for the 1.5 and 62.9 ha Giralang catchments.

To further test the procedure on independent catchments it was applied to a number of storm events on a similar scale urban catchment of 62 ha in western Sydney. This catchment indicated in Figure 2.8 is some $250 \mathrm{~km}$ north of the Giralang catchment.

The testing used the same model structure and lot parameter values. The only change related to the slight lengthening of the isochronal increment time steps from 15 to 20 seconds to allow for the Hewitt different time area characteristics.

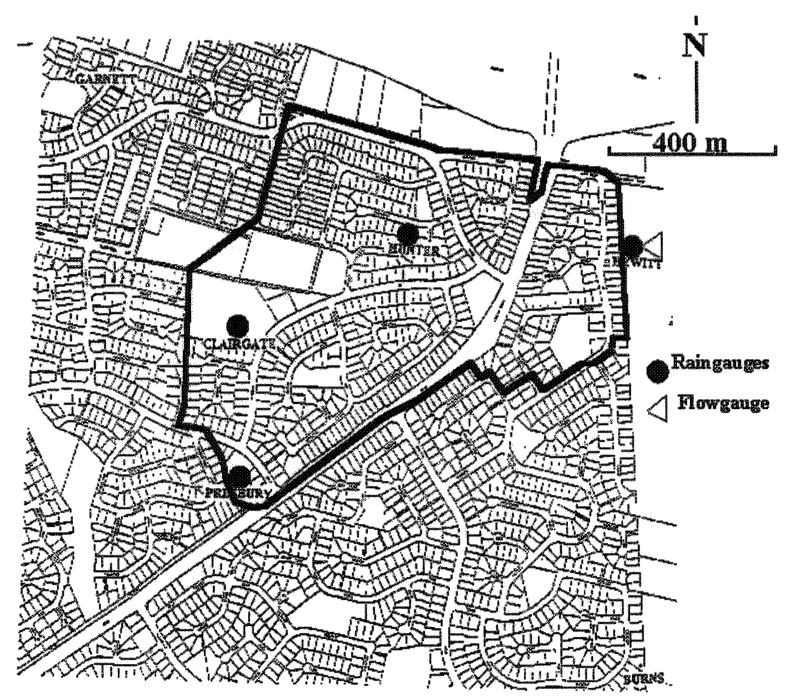

Figure 2.8 Hewitt catchment (after Wilkinson, (1995), Figure 4.1).

Even without calibration, the results were found to be satisfactory. Figure 2.9 shows the results for the main storm burst on the $15 / 2 / 94$. Some differences could be attributed to the gauged data points only being available at 5-minute intervals and the apparent differences in rainfall across the catchment indicated 


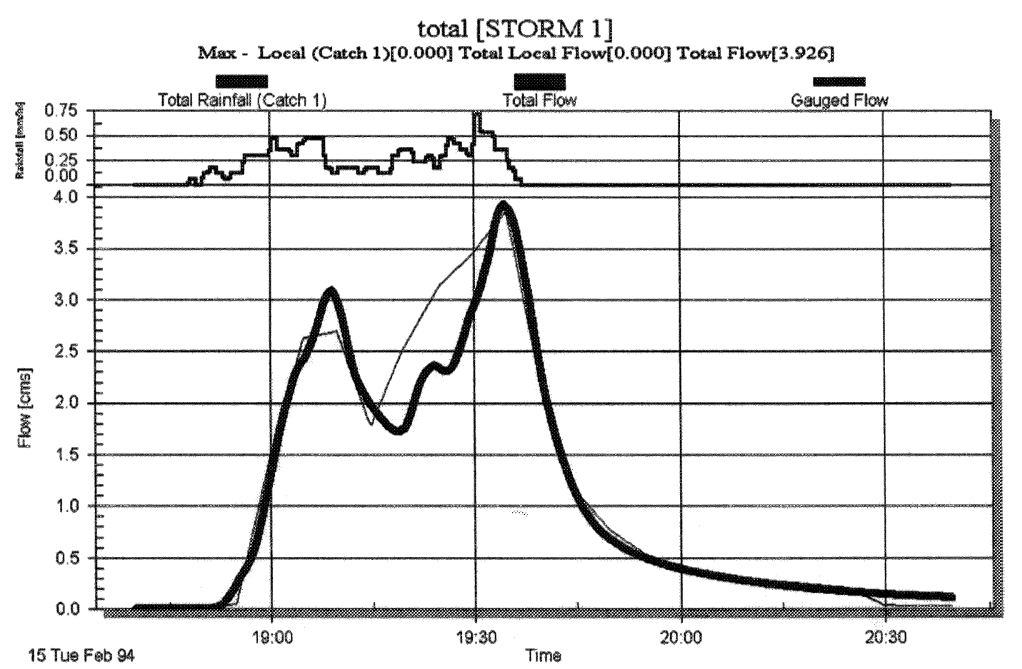

Figure 2.9 Model results for the Hewitt event of 15/2/94 (flow is in $\mathrm{m}^{3} / \mathrm{s}$, time in minutes).

from the three rainfall pluviographs within the catchment. The result was based on only a single Clairgate school rainfall station within the upper part of the catchment.

The modeling procedure is currently being applied to other Sydney urban catchments to test the viability of both water re-use roof runoff tanks as well as different lot based storage and drainage redirection systems to help reverse the effects of urbanisation on downstream waterways.

\subsection{Conclusions}

Typical urban catchments are made up of linked, recurring elements usually connected by a dendritic network of pipes and surface channels to discharge runoff to an outlet. This research has isolated a number of basic model building blocks, associated with typical residential lots that can be grouped into roof drainage, yard drainage and adjacent road drainage. A proposed modeling approach allows these blocks to be simply computed and then accumulated via the total catchment's communal drainage system's isochronal characteristics. This provides a scale-independent and storm-independent numerical approach to estimating urban runoff outputs from rainfall inputs. The procedure also allows for detailed analysis of varying lot scale runoff attenuating and reduction 
devices to potentially assist in lowering the effects of urban development on prior drainage regimes. This includes both retarding and retention devices including water reuse lot tanks.

\section{References}

Aitken A. P. (1975) Hydrologic Investigation and Design of Urban Stormwater Drainage Systems, AWRC Tech. Paper No. 10, Dept. of the Environment and Conservation, Research Project No. 71/22, Canberra

Bufill M. C. (1989) Effects of Urbanisation on Floods, PhD Thesis, University of Wollongong.

Goyen A. G. and O'Loughlin G. G. (1993). Experiences in Recent Urban IntraCatchment Monitoring. Hydrology and Water Resources Symposium, Institution of Engineers., Australia, Newcastle

Goyen A. G., Dickinson R. and Thompson. G. (1993)XP-EXTRAN the next generation unsteady flow routing system, 6th International Conference on Urban Storm Drainage, Niagara Falls, Canada

Goyen A. G. and O'Loughlin G. G. (1999) The Effects of Infiltration Spatial and Temporal Patterns on Urban Runoff, Water 99 Joint Congress, The 25th Hydrology and Water Resources Symposium, Brisbane, July

Goyen A. G. (2000) Spatial and Temporal Effects on Urban Rainfall/RunoffModelling, $\mathrm{PhD}$ Thesis, University of Technology, Sydney.

Laurenson, E.M. (1964) A Catchment Storage Model for Runoff Routing, Journal of Hydrology, Volume 2, pp 141-163

Wilkinson, A. (1995) Rainfall Variability Investigations at Hewitt, Penrith (1994-95), B.E. Thesis, School of Civil Engineering, University of Technology, Sydney 